\title{
Transversalidade da ação coletiva: a experiência em redes como possibilidade de crítica e publicização
}

\author{
Alexandre Almeida de Magalhães *
}

\section{Resumo}

O objetivo deste artigo é apresentar algumas conclusões obtidas em minha dissertação de mestrado, na qual busquei compreender como os moradores de favelas da cidade do Rio de Janeiro constituíram a luta contra a violência policial. Para demonstrar isto, utilizar-me-ei dos dados recolhidos através do acompanhamento das ações do movimento social denominado Rede de Comunidades e Movimentos contra a Violência. A análise visa explicitar o processo de publicização de certas demandas particulares e o acesso ao espaço público realizado pelos segmentos sociais subalternos. O eixo que permitirá descrever e interpretar os inúmeros agenciamentos e articulações que são tecidos pelos diversos grupos que lutam contra a violência policial em favelas nesta cidade, e que torna factível a interpretação deste processo de publicização, será o formato assumido por essa experiência: o formato em rede.

Palavras-chave: favelas, ação coletiva, redes, publicização.

\section{Introdução}

$\mathrm{O}$ objetivo deste artigo situa-se na observação do modo como os atores sociais são capazes de constituir uma ação coletiva, mesmo confrontados e inseridos em certos contextos que tornam sua atuação precária, procurando apontar as questões levantadas nas lutas por eles empreendidas e como a partir de determinadas

Doutorando em Sociologia. Instituto Universitário de Pesquisas do Rio de Janeiro (IUPERJ). Endereço eletrônico: inopiabr@ig.com.br 
demandas específicas uma ação coletiva pode ser constituída ${ }^{1}$. Além disso, o que interessa fundamentalmente a este trabalho é o processo de publicização (FREIRE, 2005) de certas demandas particulares e o acesso ao espaço público realizados por estes atores. O que se coloca aqui é a construção efetuada por estes de um processo que é capaz de tornar uma demanda particular em um problema público, passível de generalização e dos recursos que necessitam ser mobilizados neste processo. Pensar a transformação de um problema considerado privado a certos grupos em um problema que solicite uma resposta pública envolve levar em consideração que "esta ascensão ocorre durante um processo de apropriação do assunto por um determinado grupo que se considera responsável por fazer algo para resolver este problema" (ibid, p. 41).

Ao ressaltar o processo de publicização e o como dos atores sociais, pretendo romper com uma perspectiva que analisa a ação coletiva pelo signo da falta, isto é, ou pelo que os movimentos não têm ou pelo que eles deveriam ser. Mais ainda, ao ressaltar o como dos atores pretendo operar numa chave analítica que considera as capacidades destes em fazer uma crítica (BOLTANSKI \& CHIAPELLO, 1999) e os argumentos que eles acionam para definir e justificar uma situação que eles considerem como sendo injusta.

Para a compreensão da capacidade dos atores sociais em realizar uma crítica e definir uma dada situação como sendo injusta, partirei das contribuições do pragmatismo francês ${ }^{2}$, notadamente a produção que Luc Boltanski (e também Laurent Thévenot) nos oferece para o entendimento do como dos atores em relação. Segundo os autores, o terreno empírico sobre o qual começaram a trabalhar eram as disputas nas quais as pessoas trocavam críticas e elaboravam justificações. A intenção era construir um quadro que

1 Este artigo apresenta alguns resultados da pesquisa que realizei para a elaboração da dissertação de mestrado, por mim defendida em dezembro de 2008, no âmbito do Programa de Pós-Graduação em Sociologia e Ciência Política, do Instituto Universitário de Pesquisas do Rio de Janeiro (IUPERJ).

2 A Sociologia pragmatista francesa vem sendo difundida muito recentemente no Brasil, através de diversas pesquisas, sobre variados temas. Entre outros, destacam-se os seguintes trabalhos: Garcia (2009), Werneck (2008), Cunha (2008), Machado da Silva (2008), Magalhães (2008), Freire (2005). 
permitisse explicitar e unificar os constrangimentos que pesavam sobre a crítica e sobre a justificação. O objetivo principal era "sair" da sociologia crítica, suspender a posição crítica do sociólogo a fim de obter os meios para tomar a atividade crítica desenvolvida pelas pessoas ordinárias como objeto de uma Sociologia. A finalidade era a de fazer uma sociologia das competências críticas que as pessoas colocam em prática em sua vida cotidiana ${ }^{3}$ e, desta forma, procurar construir um quadro de análise das críticas e das justificações constituídos no curso das disputas.

Boltanski (2008) ressalta que a Sociologia teria, portanto, como tarefa principal explicitar, clarificar e, quando for possível, modelizar os métodos colocados em prática no mundo social para fazer e refazer os laços. Neste sentido, a Sociologia seria tratada como uma disciplina de "segundo ordem" que apresenta (em certo formato submetido a uma exigência de ordem e clareza) uma competência que seria aquela dos próprios atores. A sociologia atingiria então seu objetivo quando ela criasse um quadro satisfatório de competências sociais dos atores.

Ao invés de definir agentes por meio de atributos estáveis, de lhes assinalar interesses e disposições inscritas em seus próprios corpos capazes de gerar intenções objetivas e não conscientes, e de se propor a tarefa de explicar a ação desses atores quando confrontados com obstáculos exteriores, esta abordagem sociológica demonstraria de que modo os atores elaboram discursos sobre a ação ${ }^{4}$.

As questões acima apresentadas são de suma importância, pois o objetivo fundamental desta sociologia (também chamada de "sociologia da crítica") seria a de considerar que, em certas situações, especialmente aquelas em que as relações de força estão relativamente equilibradas, impõe-se às pessoas uma exigência de

3 Boltanski (2000) define as sociedades atuais como sendo "sociedades críticas", justamente por essa capacidade dos atores sociais em realizar críticas, estabelecerem julgamentos e justificações em suas vidas cotidianas.

4 A principal mudança observada nesta sociologia na relação entre pesquisador e pesquisados seria a renúncia a ter a última palavra sobre os atores e suas interações, no sentido de levar a sério o que eles têm a dizer e, portanto, evitar oferecer uma suposta explicação mais clara e definitiva da situação do que aquela que os próprios atores em interação possam produzir. 
justificação. O modelo se apóia na analise das justificações dadas pelos atores e, por isso, apresenta-se como sendo um modelo de competência. Esta competência não seria somente a da linguagem, mas também aquela que deve tanto permitir formar argumentos aceitáveis em termos de justiça quanto construir objetos, dispositivos duradouros cujo ajustamento pode ser comprovado. Com efeito, para evitar que as pretensões de justiça apresentadas em uma dada situação de disputa não se reduzam a manobras associadas à defesa de interesses particulares ou a ilusões sem fundamento, seria necessário mostrar de que forma estas pretensões satisfazem condições de validade que são passíveis de tolerar uma exigência de universalização (BOLTANSKI, 2000).

Como afirmam Breviglieri e Stavo-Debauge (1999), o modelo proposto por Boltanski (e também por Laurent Thévenot) permitiria descrever, sem mudar o registro da descrição, as operações cognitivas e morais colocadas em prática pelos atores para denunciar uma injustiça. Segundo Boltanski (2000), o interesse seria proporcionar um modelo que seja capaz de apontar as operações através das quais se entregam os atores sociais quando se orientam à justiça e dos dispositivos sobre os quais podem se apoiar, nas situações concretas em que se desdobram suas ações, para fundamentar desta maneira suas pretensões de justiça.

Neste sentido, e para tornar factível a interpretação do processo de publicização supracitado, irei trabalhar com a seguinte chave metodológica para a compreensão da ação coletiva: redes (ou teias) de movimentos ${ }^{5}$. Tal perspectiva é importante para os objetivos deste trabalho, haja vista que pretendo realizar um esforço analítico para apresentar uma determinada experiência de ação coletiva levada a cabo por moradores de favelas: a que se estrutura a partir da crítica a violência policial. Portanto, o eixo que permitirá

5 Importante destacar que a noção de rede será estritamente mobilizada para favorecer a descrição e interpretação deste processo de publicização e, consequentemente, de formação de uma ação coletiva. Recorrerei a esta noção, sobretudo, para aprofundar a apresentação das dinâmicas aqui apresentadas referentes à construção de um determinado movimento social. Portanto, este recurso será feito nos marcos do arcabouço teórico no qual baseio minhas análises, isto é, no pragmatismo francês ou sociologia da crítica. 
descrever e interpretar os inúmeros agenciamentos e articulações que são tecidos pelos diversos grupos que lutam contra a violência policial na cidade do Rio de Janeiro será o formato assumido por essa experiência: o formato em rede.

\section{O formato em rede: a construção da ação coletiva}

Pensar a constituição dos movimentos sociais na contemporaneidade remete-nos ao fato de considerá-los inseridos em um ambiente conflitivo cambiante que leva os atores coletivos a oscilarem entre o que Doimo (1995) denominou, por um lado, da face expressivo-disruptiva e, de outro, da face integrativo-corporativa destes movimentos. Além disso, segundo a mesma autora, estes não surgiriam mais a partir das contradições entre capital e trabalho, mas sim nos interstícios do Estado, do mercado e da cultura, possuindo uma base social não homogeneizada, pelo contrário, dispersa e volátil. Em face disto, gostaria de ressaltar o fato de que o formato constituído pelo movimento aqui analisado (isto é, o formato em rede) é uma chave para compreender a forma pela qual um conjunto determinado de indivíduos decide agir coletivamente e transformar uma demanda social específica (segurança) em uma ação coletiva e a partir desta tornar público (com pretensões à generalidade) um problema particular a certos segmentos da sociedade.

A análise da ação coletiva a partir do formato em rede, considerando o aspecto intricado de sua constituição, leva-nos a considerar o fato de que a mobilização coletiva se constitui e se efetiva de múltiplas maneiras e a partir do acionamento de inúmeros "pontos de apoio". Estes ora se referem a um conjunto de atores e grupos que se articulam a partir das mesmas questões e possuem uma "vivência comum dos problemas", ora se referem a um conjunto de atores e grupos que, mesmo não tendo a mesma experiência com certos problemas, atuam na possibilidade de operarem como articuladores e "canais de transmissão" entre grupos e instituições. Estes "pontos de apoio" também poderiam ser observados no interior do aparato do Estado, posto que a maneira de atuação em rede seria capaz de acionar indivíduos pertencentes a este de forma a integrá-los, de alguma maneira, à construção da luta. 
A importância da análise da ação coletiva a partir do formato em rede, seguindo Marques (2006), situa-se no fato de que esta perspectiva estaria localizada em um "plano de análise intermediário", visto que operaria a dicotomia entre ação e estrutura tentando superá-la no sentido de considerar o caráter simultâneo dessas duas dimensões da existência social. A unidade de análise empregada são as relações estabelecidas entre indivíduos e entre grupos (LAVALLE et alli, 2007), e, num movimento que ora se expande, ora se retrai, dependendo de determinadas circunstâncias (como por exemplo, a capacidade e a disponibilidade para a organização de certos indivíduos), entre indivíduos e grupos, e entre esses e instituições do Estado ${ }^{6}$.

O estudo das redes se torna importante a partir do momento em que permite compreender a atuação dos atores sociais em seus contextos relacionais, no fluxo das relações estabelecidas entre eles e diversos grupos e instituições, as disputas surgidas destas interações, as dificuldades para o estabelecimento de alianças, e fundamentalmente a possibilidade de observar as estratégias a partir das quais esses atores em movimento elaboram para transformar, ao acionar um "ponto de apoio" numa dada rede (ou em várias delas simultaneamente), seu problema particular em um problema público.

Com efeito, é necessário chamar a atenção para o fato de que as relações estabelecidas e as posições ocupadas nas redes constituem estruturas relacionais capazes de constranger escolhas e a darem acesso de forma diferenciada a bens e instrumentos de poder, direcionando certas alianças em uma dada direção (MARQUES, 2006). Além do mais, outro fator a ser considerado é o de que a análise realizada a partir das estruturas de relações estabelecidas em redes tem a vantagem analítica de contemplar os demais atores e grupos com os quais se estabelece algum tipo de interação, não como constituindo um "entorno", mas como parte da própria definição do ator em questão (LAVALLE et alli, 2007). Como afirmado acima ${ }^{7}$, portanto, o recurso analítico a este formato

6 É importante ressaltar o fato de que a analise do formato em redes sociais não se refere a uma sistematização teórica, mas a um arsenal analítico que pode ser mobilizado a partir de diferentes perspectivas teóricas e conceituais.

7 Ver nota 4. 
permitirá compreender como se constitui um problema público e se elabora uma ação coletiva. Busco tratar esta a partir de uma chave de leitura que a considera como sendo um processo de "codefinição e de codomínio de situações problemáticas” (CEFAII, 2008). Nesta perspectiva, acompanhar a atuação do grupo em questão (e outros que surgem, circunstancialmente, durante as mobilizações, formando intricados elos e nós), implica em considerar como a trajetória de um determinado problema público organiza um horizonte de engajamentos e de mobilizações ao seu redor.

\section{Denúncia e horizonte de publicização: do singular ao geral através da forma "caso"}

Boltanski (2000) ressalta que, no curso da construção de uma denúncia pública de injustiça por indivíduos e grupos, a posição analítica a ser tomada deveria ser a de se questionar sobre qual condição deve satisfazer tal denúncia para que seja considerada admissível (por outros indivíduos e grupos). A proposição analítica aventada por Boltanski aponta para a constituição da forma "caso" (affaire) como possibilidade de explicitação dos processos que levam a construção de denúncias públicas. Segundo o autor, a observância de um caso permite verificar o fato de que quem protesta o faz porque seu sentido de justiça foi ofendido. Esta forma de denúncia traduziria, portanto, um senso de injustiça, o esforço de formação de uma causa, que sempre se refere a algum coletivo (FREIRE, 2005) ${ }^{8}$.

Para Boltanski, o estudo dos casos supõe a renúncia em qualificar previamente o objeto de estudo e, particularmente, em estabelecer suas dimensões. O autor apresenta um exemplo. Se uma secretária protesta contra alguma injustiça, obstina-se em seu protesto sem conseguir mobilizar uma quantidade razoável de pessoas nem comprometer a favor de sua causa representantes

8 Contudo, antes mesmo de examinar se estão ou não em seu legítimo direito, dever-se-ia resolver outra questão, referente à pré-condição da admissibilidade da própria demanda: a de saber se quem a formula é ou não "normal". Isto se coloca, pois existiria uma coação constituída pelas regras de normalidade às quais o autor da queixa precisa levar em consideração para que sua demanda seja considerada como digna de ser examinada. 
de certas instituições, sindicatos, jornalistas, seu problema será considerado e tratado como sendo de ordem meramente pessoal. Seu protesto segue sendo um caso singular. Mas, ao contrário, se seu protesto é considerado e se ela consegue que outros a sigam, se algumas instâncias autorizadas ${ }^{9}$ (assim como os sindicatos) estabelecem uma equivalência entre seu caso com outros de mesma natureza; se seu caso, definido agora como "exemplar", passa a ser utilizado a serviço de uma causa que se torna "geral", poderá como consequiência ampliar-se, mobilizando um número considerável de pessoas e ascendendo ao status de problema coletivo.

A essa observação associa-se outra de caráter metodológico: longe de aceitar a separação a priori entre o que é individual e o que é coletivo, o sociólogo deve tratar a qualificação do caso como sendo o produto da própria atividade dos atores. Ao invés de ocupar-se com coletivos plenamente (e anteriormente) constituídos e, de certa maneira, já preparados para seu uso, pode (e deve) apreender as operações de construção dos coletivos examinando a formação das causas coletivas, ou seja, da dinâmica da ação política.

Levando isso em consideração é que pretendo apresentar as condições de formação de uma experiência de ação coletiva constituída na cidade do Rio de Janeiro: aquela que se articula em torno da temática da violência policial através da Rede de Comunidades e Movimentos contra a Violência. Este movimento social se define por se referir a um grupo bem específico: os moradores de favelas desta cidade. Esta experiência será abordada aqui através da forma caso, como aventado acima. A apresentação do caso que permitiu a criação deste movimento social tem o intuito de fornecer instrumentos para a compreensão de como (e a partir do que) se articulam diversos atores sociais que lutam contra a violência policial ${ }^{10}$.

Constitui-se como um "caso exemplar" por encerrar em si um conjunto de sentidos e práticas capazes de aproximar uma quantidade incomensurável de casos que se espraiam pela cidade. Refere-se a uma chacina ocorrida numa favela da Zona Norte da

9 Legitimadas e reconhecidas coletivamente.

10 É importante ressaltar o fato de que o número de casos é considerável e não é a intenção deste trabalho examinar a totalidade destes. 
cidade, fato que originaria posteriormente a Rede de Comunidades e Movimentos contra a Violência, cuja atuação se configura como a base da análise que pretendo realizar da luta empreendida contra a violência policial.

Vamos ao caso. Em 2003, quatro jovens foram mortos em uma operação policial na favela do Borel, no bairro da Tijuca, Zona Norte do Rio de Janeiro. A polícia justificou as mortes afirmando que esses jovens eram integrantes dos grupos criminosos enquistados nesta favela. Logo depois, descobriu-se o contrário: não eram jovens ligados ao crime. Descobriu-se também que não tiveram direito à defesa: foram sumariamente mortos. Os laudos cadavéricos que então foram elaborados apontavam que, ao serem mortos, ou a posição dos braços demonstrava uma tentativa de proteger o corpo contra os disparos, numa postura que os colocavam de forma cruzada, ou que receberam os tiros pelas costas. Um dos jovens, antes de ser morto nesta investida da polícia, ainda tentou, em vão, identificar-se, o que foi prontamente ignorado pelos policiais que o abordaram.

Foi a partir deste caso (mais um caso) que um grupo de moradores, movimentos sociais e ONGs (Organizações Não-Governamentais) se organizaram para constituir um movimento que lutasse contra a violência policial. Este movimento ficou conhecido inicialmente como "Posso me identificar?", nome dado em alusão a uma das últimas frases ditas por um dos jovens mortos na Chacina do Borel. Esta se transformou em um acontecimento catalisador, acabando por gerar uma combinação entre sentimentos como sofrimento, dor e medo e um posicionamento político que demandava respeito pelos direitos dos moradores de favelas, além da exigência por justiça.

Nesse período, diversas ações foram feitas, inclusive a realização de duas grandes manifestações, a primeira ocorrida em 2003, denominada "Caminhada Borel pela Paz", que se realizou no mesmo bairro onde se encontra a favela. A segunda ocorreu exatamente um ano depois (2004) da morte dos quatro rapazes, desta vez nas ruas que levam à sede do governo estadual. 0 desenrolar dessas ações foi decisivo para os rumos que o movimento tomaria a partir de então. Em decorrência das divergências internas quanto ao formato de atuação do grupo, haveria uma subsequiente divisão no interior deste. Isso ocorreu devido às visões diferenciadas que cada um 
possuía sobre qual deveria ser a atuação política e as estratégias de luta. Como afirma Farias (2007): "nem todos os integrantes do grupo concordavam com a manutenção de estratégias de atuação política marcadas por ações reivindicatórias, atos públicos e atividades afins. Acreditavam que os esforços poderiam ser concentrados na construção de uma sede para o grupo - um espaço onde pudessem funcionar cursos e oficinas para os jovens moradores de favelas"

As divergências no interior do "Posso me identificar?" chegariam a tal ponto que, no segundo semestre de 2004, o grupo se dividiria em dois blocos, entre aqueles que consideravam necessária a organização de atos públicos de forma contínua, denunciando as constantes violações dos direitos humanos nestas localidades, exigindo do poder público a garantia aos direitos fundamentais dos moradores de favelas, com vistas a um maior acesso aos bens e serviços de cidadania, e os que afirmavam que as atividades para as quais o grupo deveria se orientar eram aquelas exercidas através de projetos pontuais, principalmente cursos de capacitação profissional oferecidos aos jovens.

Portanto, após completar um ano das mortes desses quatro jovens, e depois da realização desse ato em frente ao palácio do governo do estado, esse movimento mudaria sua denominação, passando então a se chamar "Rede de Comunidades e Movimentos contra a Violência" 11 , forma encontrada para dar cabo às disputas que então ocorriam.

A "Rede"12 é constituída por uma diversidade de indivíduos e grupos internos, que envolve: militantes que não são moradores de favelas, mas que atuam em movimentos sociais urbanos em favelas e periferias da cidade; moradores de favelas que possuíam algum tipo de atuação política dentro e fora da favela; e por familiares de vítimas da violência policial. Este último grupo, segundo os próprios

11 Para maiores esclarecimentos sobre a origem tanto do movimento "Posso me Identificar?" quanto da Rede de Comunidades e Movimentos contra a Violência, ver Farias $(2004 ; 2006)$. Algumas informações sobre a Rede tiveram por base o trabalho desta autora sobre esse movimento social.

12 A partir de agora irei me referir a este movimento social apenas como "Rede", assim como seus integrantes o tratam quando da necessidade de se apresentar no espaço público. 
integrantes da Rede seria a base de sustentação da atuação deste movimento. A persistência e o aumento do número de mortes ocasionado por incursões policiais em favelas da cidade fazem com que o movimento não perca a direção dos objetivos ansiados, isto é, a luta contra a política de segurança pública do Estado do Rio de Janeiro e a imagem corrente na cidade que atualiza cotidianamente uma "prática de extermínio" contra os moradores pobres da cidade e em especial os moradores de favelas (FARIAS, 2007).

Discuto, a seguir, como se configura a atuação da Rede. Realizar isto é entender, desde já, as inúmeras interconexões que estabelece ao agir e desta maneira a considerável quantidade de atores e grupos que se encontram presentes nesta atuação. A observação destas interconexões não passa pela descrição exaustiva de todos os grupos que forem citados adiante, pois tomarei como ponto de partida sempre a atuação da Rede e as relações que este movimento estabelece (ou estabeleceu), tentando perseguir alguns caminhos que possibilitam compreender a complexidade da construção da violência policial como um problema público e, consequetemente, da ação coletiva por moradores de favelas da cidade do Rio de Janeiro.

A Rede de Comunidades e Movimentos contra a Violência, como afirmado acima, constitui-se a partir da incorporação de diversos grupos e indivíduos, com origens e histórias particulares diversas. Familiares de vítimas, integrantes de outros movimentos sociais urbanos, indivíduos que tiveram a Rede como a primeira experiência de ação coletiva, formam um intricado grupo, que apesar do nome, não é uma "rede em si”. Sua denominação parece expressar mais um objetivo do que propriamente a constituição do grupo, visto que o próprio termo encerra uma pretensão de fluidez, mais do que de rigidez. A palavra "rede" pode ser compreendida como um formato no qual os grupos interagem, um formato que se apresenta sempre em processo, portanto, que se modifica constantemente. $\mathrm{Na}$ apresentação dos objetivos do grupo é possível perceber, no que se refere à sua forma de atuação, alguns dos objetivos principais, como por exemplo, a construção de uma rede de apoio jurídico às favelas contra a violência policial e de uma rede de denúncias, a nível nacional e internacional. 
A fim de garantir a efetivação deste apoio jurídico, a Rede formulou em 2007 um convênio com o Instituto de Defensores dos Direitos Humanos (IDDH) ${ }^{13}$, Organização Não-Governamental que pretende constituir uma rede de profissionais do Direito com o objetivo de garantir juridicamente os direitos daqueles que foram vítimas de violência policial, bem como de possibilitar o encaminhamento dos casos de uma maneira mais célere no interior dos aparatos judiciais.

O convênio estabelecido entre a Rede e o IDDH tem como principal objetivo suprir a insuficiência de assessoria jurídica aos moradores de favelas, principalmente em casos de violação dos direitos humanos nestas localidades. É importante ressaltar o fato de que, muito antes da formulação deste convênio, havia a colaboração de uma série de advogados e mesmo de representantes do Ministério Público, embora não de uma maneira formal. Mesmo alguns integrantes do atual IDDH já colaboravam com a Rede antes da criação do instituto, bem como em outros movimentos sociais no Rio de Janeiro.

A intenção deste convênio era possibilitar que o crescente número de casos de violação de direitos humanos em favelas tivesse uma garantia maior de que fossem solucionados, haja vista que, para além das dificuldades habituais enfrentadas pela população da cidade como um todo quando do acesso à justiça (principalmente devido à demora na resolução dos processos), existem os problemas decorrentes do fato de que este acesso é ainda mais dificultado às classes subalternas, especialmente os moradores de favelas. Neste sentido, este convênio teria como pretensão superar uma imensa dificuldade que seria a de garantir a possibilidade de exercer uma maior pressão para que casos como o do Borel sejam investigados, que se transformem em processo e que este tenha um encaminhamento favorável aos familiares de vítimas de violência policial.

13 Esse grupo foi formado a partir da Chacina do Alemão (analisada na primeira parte desta dissertação) no ano de 2007. Seus integrantes pertenciam à Comissão de Direitos Humanos da Ordem dos Advogados do Brasil (OAB) e se retirariam desta comissão em solidariedade ao então presidente que foi exonerado após solicitar a realização de um relatório independente, com base em laudos do Instituto Médico Legal, organizado por um perito que não estivesse de alguma maneira envolvido com os casos surgidos desta chacina. O grupo formador deste núcleo fundaria ao final do mesmo ano o IDDH. 
Um dado interessante surge quando da tentativa de expansão desta "rede jurídica". Ao apresentar esta proposta de convênio a outros grupos e instituições, como o Centro de Assessoria Jurídica Mariana Criola ${ }^{14}$ e ao Ministério Público do Estado do Rio de Janeiro (MPRJ), militantes da Rede encontraram dificuldades ao tentar formalizá-lo, especialmente com relação a esta última instituição. Ao proporem ao Subprocurador de Justiça de Direitos Humanos e Terceiro Setor do Estado do Rio de Janeiro o estabelecimento de um acordo nos moldes daquele instituído com o IDDH, o jurista questionou a possibilidade deste se efetivar, posto que não seria possível, legalmente, um convênio de uma instituição com uma pessoa física.

Esta situação assim ocorreria, pois o acordo firmado com o IDDH foi realizado entre pessoas físicas, constituído por assinaturas individuais de militantes da Rede, do próprio IDDH e mais um representante da favela onde o acordo foi feito, como testemunha. Nesse momento podemos perceber um impasse: como a Rede, enquanto movimento social, não possuía existência jurídica através do Cadastro Nacional de Pessoas Jurídicas (CNPJ), o convênio com o Ministério Público não poderia se realizar, não pelo menos nessas bases. Diante da necessidade de garantir maior segurança jurídica aos moradores de favelas e de ampliar as possibilidades de solução legal dos casos de violação dos direitos humanos nestes territórios, a Rede conjeturava que a contribuição de uma instituição como o Ministério Público seria de suma importância ${ }^{15}$.

Este fato demonstra não somente os percalços atravessados pelos diversos movimentos sociais, principalmente aqueles organizados por moradores de favelas, mas ao mesmo tempo certa visão de como o movimento deve se constituir e atuar na esfera pública. Para uma das militantes em questão, envolvida naquela situação, não

14 Este centro também tem como objetivo oferecer assessoria jurídica a organizações e movimentos sociais populares, bem como oferecer acesso ao conhecimento jurídico. A entidade foi criada em dezembro de 2006 por um grupo de advogadas e estudantes que atuavam em conjunto com diversas organizações populares de maneira coletiva e voluntária.

15 Interessante notar que as militantes designadas a oferecer a possibilidade deste convênio ao representante desta instituição, classificariam como "curiosa" a atitude do subprocurador em interrogá-las sobre a necessidade da Rede em possuir um CNPJ, pois sem este nada seria possível fazer. 
fazia sentido o questionamento feito pelo subprocurador de justiça, visto que a Rede não se articularia enquanto uma instituição formal e burocrática, mas como um movimento social, o que leva em consideração o fato de que sua constituição e articulação com outros atores coletivos independem de uma formatação jurídica e burocrática.

\section{A rede enquanto canal de denúncias e o capital social de conexões: a dupla face de um mesmo processo}

As possibilidades que uma denúncia tem para ser entendida como normal ou anormal depende do grau de proximidade ou distância daqueles que se encontram envolvidos no caso. $\mathrm{O}$ ato de denúncia pública coloca em perigo não apenas o indivíduo ao qual se direciona, mas igualmente o conjunto da comunidade a qual pertence tanto o acusador, quanto aquele que é perseguido. A fim de que uma denúncia seja reconhecida como válida (e, claro, julgada como normal), coloca-se a necessidade de que dois actantes ${ }^{16}$ diferentes suportem seu peso. Ou seja, haveria a necessidade, por um lado, da pessoa da vítima, aquela que sofreu alguma injúria denunciada, e por outro, a figura do acusador, que a torna conhecida

16 Retomando reflexões iniciadas em um trabalho que discutia a formação dos cadres (quadros) na França entre as décadas de 1930 e 1960, Boltanski afirma que a sistematização dos dados e sua análise posterior se sustentariam a partir de duas operações sem as quais o trabalho não teria sido possível. Por um lado, a constituição de um júri, composto por pessoas comuns que colocaram em jogo seu sentido corrente da normalidade e da justiça (noções que, para Boltanski, andam juntas) e que se encarregaram de outorgar, quando da primeira leitura rápida dos documentos que lhes chegavam, uma qualificação de normalidade a cada expediente. Por outro lado, a definição de um sistema actancial da denúncia que compreende quatro actantes: uma vítima, um denunciante, um perseguidor e um juiz. O sistema actancial, de acordo com Boltanski, é um modelo que teve origem na linguíística, como a intenção de associar o inventário de funções dos personagens às funções sintáticas da língua. Cada um deles foi codificado segundo um tamanho sobre um eixo singular-geral. Construir o quadro analítico desta maneira possibilitaria, afirma Boltanski, a substituição da oposição individual/coletivo pela oposição singular/geral, o que autorizaria a diversificação das operações concebíveis sobre esse eixo na qual a passagem do individual ao coletivo não seria mais que um caso particular. Com este sistema muito geral de codificação, afirma o autor, poder-se-ia integrar todos os casos reunidos na pesquisa. 
da opinião pública. $\mathrm{O}$ desdobramento entre a vítima e aquele que realiza a acusação pública de alguma injustiça ou injúria sofrida, garante que os interesses comprometidos não sejam meramente individuais (BOLTANSKI, 2000, p.263) ${ }^{17}$.

Em relação aos integrantes da Rede, para além da figura do acusador, aquele especificado para tornar pública uma dada denúncia, o que parece se constituir seria o fato de o movimento como um todo se transformar (e se compreender enquanto tal) em um "canal de denúncias", construindo uma espécie de "ponte" entre as denúncias realizadas por moradores de favelas em casos de violência policial e as instituições públicas e a sociedade de uma maneira geral. Neste momento, retomamos um dos objetivos do próprio grupo, no que se refere a sua forma de atuação, que seria a constituição de uma rede de denúncias capaz de tornar público os diversos casos de mortes de moradores de favelas provenientes das incursões policiais nestas localidades, justificadas pela necessidade de se "combater" a criminalidade violenta.

Os dados recolhidos em meu trabalho de campo permitiram compreender os significados envolvidos na atuação da Rede, fundamentalmente no que se refere a tornar possível que denúncias de violência policial ganhem publicidade e, desta maneira, haja alguma forma de julgamento dos envolvidos e, consequentemente, garanta aos familiares de vítimas o sentimento de que "a justiça está sendo feita”, apesar das inúmeras dificuldades. O objetivo, se assim o podemos definir, seria possibilitar que o fluxo de queixas e informações tenha um direcionamento e não se perca nos inúmeros desvios ao longo do caminho de construção e efetivação de uma dada denúncia ${ }^{18}$.

17 Para que o apoio oferecido a uma vítima seja capaz de exercer o efeito de mobilização sobre outros indivíduos, seria necessário que se pudesse não apontar nada que permitisse levantar suspeitas sobre a existência de um nexo entre o acusador e a vítima capaz de estabelecer um interesse que seja comum a ambos, posto que o que deve uni-los é o mesmo objetivo de bem comum. Ou seja, estes actantes não poderiam ser acusados de darem curso a interesses particulares, não restando dúvidas quanto a sua pretensão a generalidade.

18 Estes desvios representam tanto obstáculos simbólicos, visto que a construção de um conjunto de "imagens negativas" contra os moradores de favelas tendem a limitar seu acesso aos aparatos de justiça, quanto materiais, no que se refere aos custos financeiros envolvidos que podem dificultar ainda mais este acesso. 
A atuação da Rede, neste sentido, caracteriza-se e efetiva-se fundamentalmente pelo fato de muitos de seus integrantes conhecerem os caminhos necessários que precisam ser percorridos para que uma denúncia seja reconhecida e tenha algum tipo de tratamento público, ainda que muitas vezes apenas institucional. O papel do acusador (que aqui podemos compreendê-lo como um mediador entre os moradores, isolados e muitas vezes sem conhecer os trâmites necessários para dar curso a sua denúncia, ou mesmo pelo medo em realizá-la) parece fundamental:

"normalmente encaminho para o Ministério Público, eu recebo denúncias, às vezes, repasso as denúncias também, acompanho em delegacia, às vezes vejo inquérito ... porque assim, eu não sou advogada, então eu tenho um ponto complicadão para mim poder ter acesso à inquérito. Mas se você estiver com familiar, você consegue" (militante da Rede) ${ }^{19}$

Como se pode observar nesta citação, embora a atuação individualizada de um morador que foi ou teve um familiar vitimado seja muita vezes impossibilitada pelas dificuldades que aqueles que moram em favelas encontram no acesso à justiça, a possibilidade de asseverar o encaminhamento das denúncias, por parte daquele que é o acusador (ou o mediador, no caso o militante da Rede), somente se concretiza quando os dois actantes se encontram próximos. Isto se dá na medida em que apenas com a presença da vítima seria factível, nesta situação em específico, por um lado, acessar uma parte importante de uma investigação - que é o inquérito - e, simultaneamente, de outro lado, a presença do acusador seria capaz de facilitar, em certa medida, o encaminhamento mais acelerado da denúncia, visto que a experiência longamente adquirida ao acompanhar casos como esses possibilita encurtar os caminhos necessários que precisam ser percorridos no interior do aparato policial e judicial. A experiência obtida ao longo do tempo permitiria até mesmo uma "ligação direta" com aqueles que podem abreviar o processo de denúncia e sua resolução: "E alguns, não vou dizer todos os delegados, a maioria eu conheço, então o acesso já é fácil.

19 Entrevista por mim realizada em julho de 2008. 
Já vou direto (...) Já vou direto na pessoa certa. Normalmente eu encaminho para o Ministério Público, diretamente"

Esta experiência acumulada durante anos, que se expressa através de uma trajetória de vida particular, pode ser percebida até mesmo na possibilidade de relação com agentes da instituição policial, que em muitos momentos parece inalcançável, principalmente em se tratando de um morador de favela. Quando questionada sobre se já havia encaminhado denúncias à delegados e integrantes da estrutura policial, a militante afirma:

Já, já... e assim, ele me deu a resposta em menos de 24 horas, realmente, e ele mesmo conseguiu prender os caras. Era um delegado que eu conhecia, que eu confiava nele e que eu sabia que ele não ia me jogar na lenha. Se eu passasse uma denuncia ... eu tava até conversando, eu cansei de passar denúncia para o (chefe da Polícia Civil do Estado). Eu não faço idéia o que ele fez com essas denúncias. Muita coisa. Apesar de que nunca me aconteceu nada, mas aí a gente fica com ... eram denuncias graves. Fica com o pé atrás. O (chefe de gabinete), que era pessoa de confiança dele. Cansei de repassar. Ele era a pessoa de confiança do (chefe da Polícia Civil)"

Esta passagem demonstra que, apesar da relativa facilidade encontrada por esta militante em acessar inclusive a estrutura de uma instituição como a Polícia Civil, as relações entre aquele que atua em um movimento social, que tem por eixo de articulação a violência policial em favelas, e integrantes desta estrutura, são revestidas de tensão e a confiança devotada pela militante a estes agentes do Estado se configura de uma maneira frágil e muito pontual, podendo ser rompida a qualquer momento.

A expansão das ações do movimento em questão pelo tecido social permite apontar outro elemento, que parece definir de maneira decisiva os limites do grupo, assim como as possibilidades de sua ampliação e sua capacidade de obter apoios: as experiências apresentadas em situações de disputa expressam o acúmulo de "capital social de conexões" (VANDENBERGHE, 2006). Este acúmulo é o que favorece (e o que tem favorecido) a extensão da atuação deste movimento, bem como vem permitindo a própria continuidade do mesmo ao longo do tempo. Como afirmado anteriormente, os indivíduos e grupos que constituíram a Rede de 
Comunidades e Movimentos contra a Violência possuem trajetórias particulares distintas, expressando experiências diversas quanto à própria concepção de como se deve organizar uma ação coletiva, mas, sobretudo, trazendo consigo uma quantidade considerável de conhecimentos quanto a práticas organizativas, contatos pessoais que possibilitam que ações planejadas possam ser levadas adiante, assim como um cabedal de repertórios de estratégias de luta que estimulam a participação de seus integrantes.

A maioria daqueles que formam a Rede teve alguma experiência anterior, quer seja no movimento sindical, quer seja em ações coletivas em determinadas favelas, quer seja em outros movimentos sociais urbanos, quer seja ainda em movimentos de mães e de familiares de vítimas ou em outras modalidades de mobilização coletiva. Entretanto, essa experiência apenas se tornou possível a partir de dois elementos intrinsecamente relacionados: o engajamento em certas lutas e o tempo. Quanto a este último, é possível perceber como são importantes, para a continuidade das ações e também, no caso da Rede, na relação com os familiares de vítimas (no sentido da confiança na atuação destes militantes, visto que eles conhecem o "caminho das pedras") os conhecimentos obtidos ao longo do tempo na prática cotidiana das lutas nas quais seus integrantes se encontraram envolvidos, o que thes permitiram adquirir capacidades que os possibilitam proceder nas diversas situações surgidas, bem como tornar ágil sua movimentação em múltiplos espaços, mesmo aqueles aparentemente fechados, como o judiciário.

Quanto ao engajamento, este não pode ser considerado como um elemento dissociado do tempo, ao contrário, são duas dimensões que se articulam na acumulação de capital social de conexões e que colaboram na atuação e expansão dos movimentos sociais. No que se refere à Rede, este parece ser um dos artifícios que garantem, por um lado, não apenas a diversidade interna do grupo (visto que muitos passaram por outras experiências de atuação política) e, por outro, a concentração de conhecimentos adquiridos no tempo (justamente por estas experiências anteriores), mas também demonstra que esta reunião de pessoas que formou a Rede possui um caráter flexível, aberto e isso parece ser o que, em diversas ocasiões, facilita a própria atuação deste grupo. 
Entretanto, apesar deste engajamento representar formas diferenciadas de inserção e também trajetórias distintas de envolvimento político, e este movimento em específico apresentar-se aberto para articulações que envolvam outros grupos e indivíduos, este tipo de estruturação por redes e impulsionado pelo capital social de conexões (propiciado pelas histórias pessoais dos integrantes) parece estabelecer certos limites quanto à capacidade para absorver divergências ideológicas e políticas muito conflitivas, assim como afirma Scherer-Warren (2006). Isto é importante, pois, a possibilidade de que suas ações se realizem, bem como as articulações que fez, faz e fará dependem de certa postura ideológica que propiciem um consenso mínimo que garanta a mobilização e atraia mais adeptos e assim permitir que a própria luta tenha continuidade, no tempo e no espaço.

Posto isto, cabe verificar como se efetiva este engajamento, bem como a articulação deste movimento social com outras organizações de direitos humanos na construção de denúncias públicas. Mais ainda, vale apresentar algumas das maneiras através das quais é possível realizar uma crítica pública, principalmente a partir de formas de mobilização coletiva e de atos públicos.

\section{Modos políticos de acentuação: a campanha contra o "caveirão" e o Tribunal Popular}

A denúncia pública para se efetivar e ser reconhecida como normal (ou coletivamente legitimada) dever satisfazer certas condições. Para analisar os deslocamentos sobre o eixo particular-geral seria necessário levar em consideração as coações de normalidade, que contribuiriam para definir o que é aceitável criticar privadamente ou denunciar publicamente.

Segundo Boltanski (2000), uma denúncia de injustiça aparece como anormal quando os diferentes actantes não ocupam a mesma posição sobre o eixo singular-geral. O que aparece como anormal seria precisamente as manobras que os queixosos desenvolvem para conseguirem engrandecer-se e, em consequiência, para colocarem-se a altura do juiz a quem submetem seu caso. A anormalidade con- 
sistiria em denunciar a injustiça ${ }^{20}$ sofrida em situações que não se referem a ela, diante de pessoas, individuais ou coletivas, que não lhes são apropriadas. Deste modo, poder-se-ia dizer que a origem da anormalidade seria em primeiro lugar cognitiva ${ }^{21}$ (op. cit., 2000). Consistiria fundamentalmente em efetuar uma denúncia em uma dada situação que não permitiria a anuência dos actantes de mesmas dimensões. De modo a escaparem aos rigores do juízo de normalidade que se apresentam em situações de disputa, a melhor forma encontrada pelos denunciantes seria o recurso a modos políticos de acentuação (op. cit. p. 299), isto é, realizar atos que ponham em jogo a interpretação no registro da política e também fazer referência a algum ente coletivo, em cujo nome se é permitido falar e autorizado a se expressar ${ }^{22}$.

Estes modos políticos de acentuação podem ser percebidos através da formulação de atos e protestos no espaço público, mas também da realização de campanhas, que se configuram como um dos elementos importantes capazes de mobilizar o conjunto dos indivíduos envolvidos, em especial aqueles pertencentes à Rede, mas, sobretudo, um emaranhado de grupos e atores que compartilhem as mesmas críticas à violência policial e à política de segurança pública no Rio de Janeiro.

Uma das principais mobilizações na qual a Rede possuiu envolvimento ativo foi a "Campanha Contra o Caveirão", realizada em 2006 em parceria com outras instituições e movimentos sociais, como a Anistia Internacional, a Justiça Global e o Centro de Defesa

20 É importante ressaltar o fato, salientado por Boltanski, de que a injustiça pode ser expressa em registros diferenciados: no discurso político (ou sindical), bem como cotidianamente, em uma conversa entre amigos, ao telefone, na família, etc. Apontar para esta ordem de considerações é afirmar que em nossas sociedades, os indivíduos possuem capacidades críticas e podem mobilizar, ainda que de modo desigual de acordo com a situação estabelecida, recursos críticos que põem em prática no curso de suas ações cotidianas.

21 Uma denúncia não é julgada como anormal quando os actantes ocupam posições homólogas sobre o eixo singular/geral.

22 Este é o pólo superior de uma escala de denúncia em que podemos encontrar, no seu pólo oposto, os gestos simbólicos de protestos e de mobilização que um indivíduo, a vítima ou aquele que a representa, é livre para realizar por si mesmo, sem a assistência de outros, e muitas vezes sem obter o apoio que esses atos almejam. 
dos Direitos Humanos de Petrópolis. A realização desta campanha possibilita compreender como se configura uma das maneiras de uma dada rede de movimentos se articular, bem como de colocar em jogo seu senso de justiça, que, na situação em questão, exclui o recurso universal a violência como forma de enfrentar a criminalidade violenta.

Este veículo, intitulado "pacificador" pelas autoridades, teria como intenção principal a de servir de apoio às operações do Batalhão de Operações Especiais (BOPE) da Polícia Militar do Rio de Janeiro ${ }^{23}$ nas incursões feitas por esta instituição nas favelas da cidade e do estado. Ele é conhecido pelos moradores de favelas como "caveirão", alusão ao emblema do BOPE, que se situa nas laterais do veículo, formado por uma caveira, transpassada por uma espada em cima de duas armas douradas. $\mathrm{O}$ argumento mobilizado para justificar a utilização deste equipamento é a garantia de proteção dos policiais em serviço, dado que a situação de "conflito" enfrentada por eles nessas localidades requer algum tipo de garantia mínima de retornar dessas investidas com vida ${ }^{24}$.

Seria a partir do contexto de utilização deste equipamento que se formularia a Campanha contra o Caveirão. No dia 13 de março de 2006, a Rede, os movimentos sociais e ONGs acima mencionados, lançaram a campanha, a nível internacional, num ato realizado no Centro do Rio de Janeiro, que defendia o fim imediato da utilização

23 É importante ressaltar o fato de que, atualmente, não apenas o Batalhão de Operações Especiais (BOPE) utiliza este veículo blindado conhecido como "caveirão". Outros grupos especiais também o utilizam, como por exemplo, o CORE, Coordenadoria de Repressão à Entorpecentes, da Polícia Civil.

24 Muito além de ser uma nova "arma" na luta contra a violência, notadamente a violência ligada ao tráfico de drogas e de armas, a utilização deste veículo nas incursões da polícia nas favelas materializa, como apontando na parte anterior deste trabalho, o tipo de formulação e percepção, consolidada pela opinião pública dominante na cidade, de que a situação vivenciada na cidade e no Estado se trata de uma guerra contra um território específico. Mais do que ser uma nova forma de agir das forças de segurança estatais, o "caveirão" tem se tornado a principal arma que continua, tanto materialmente, mas principalmente simbolicamente, "exterminando" a população residente em favelas. Identificados como alheios à ordem da cidade e também como colaboradores dos criminosos ligados ao tráfico enquistados nesses espaços, nessa situação de "conflito" lhes são negados todo e qualquer direito. Especialmente o direito a própria vida. 
do blindado pela PM nos territórios da pobreza no Estado. Esse era o alvo principal e mais imediato da campanha. Contudo, a intenção era ir além disso. Era questionar a política de segurança pública construída pelo Estado, assim como desconstruir o imaginário fortemente negativo contra os moradores de favela.

Uma das formas de mobilização da campanha foi a realização de um abaixo-assinado cuja função seria a de recolher assinaturas que seriam encaminhadas ao governo do Estado. A outra forma de mobilização e pressão era um postal que deveria ser preenchido, especialmente por aqueles residentes fora do país - visto que era uma campanha internacional - e encaminhados diretamente ao governo estadual. Após esse ato de lançamento ${ }^{25}$, portanto, as atividades se concentrariam na mobilização das entidades e pessoas envolvidas para recolherem o máximo de assinaturas possível e encaminhá-las ao governo.

A campanha, e seus instrumentos para conquista de apoios (o abaixo-assinado e o postal), apontavam para a necessidade de que os casos de violação de direitos humanos em favelas não poderiam ficar restritos apenas ao Rio de Janeiro, mas também possuírem notoriedade para além das fronteiras do próprio país, o que se verifica no acionamento de instituições internacionais (como a Anistia Internacional), cuja atuação em outros países pudesse favorecer a arregimentação de mais e novos apoios, capazes de atuarem em conjunto na elaboração das denúncias, assim como na circulação destas por diversos espaços e instituições.

Num ato realizado em frente à sede do governo estadual em junho de 2006, a Campanha Contra o Caveirão, após formar uma pequena comissão, entregou o abaixo-assinado. Entretanto, a reivindicação imediata, qual seja, a da suspensão da utilização, pela PM, do blindado conhecido como "caveirão", não aconteceu. Apesar disso, segundo relato dos próprios organizadores da campanha e

25 Participaram deste ato de lançamento inúmeras organizações da sociedade civil e movimentos sociais, como os próprios idealizadores da Campanha, assim como as Mães do Caju, mães que tiveram seus filhos vitimados pela violência, Movimento dos Sem-teto, Gente Viva, Central de Movimentos Populares, Movimento Moleque, Comitê Suíça, representantes de associações de moradores e muitos outros. 
representantes dos movimentos que construíram a mesma, a campanha teve sucesso em parte. Isso porque, se não teve a dimensão esperada dentro das próprias favelas em que o "caveirão" é utilizado, ela entrou no debate político, visto que se estava em plena campanha eleitoral para o governo do Estado naquele ano ${ }^{26}$.

A necessidade de conquistar maior visibilidade para suas ações, bem como facilitar o encaminhamento de denúncias para assim torná-las públicas, fez com que, cada vez mais, movimentos sociais como a Rede, articulassem-se a outros grupos que compartilhassem dos mesmos ideais políticos e ideológicos e que estivessem inseridos no mesmo "campo ético-político" (DOIMO, 1995) e assim terem maior capacidade de causar algum impacto na esfera pública, institucional ou não.

Na configuração de um amplo processo articulatório, do qual é improvável conhecer todos os elos estabelecidos, estes movimentos acabam por conferir legitimidade às esferas de mediação, tais como fóruns e redes, constituídas entre, por um lado, os movimentos e o Estado e, de outro lado, entres estes mesmos movimentos através de redes com certa autonomia (SCHERER-WARREN, 2006). Neste último sentido, e ainda considerando os modos políticos de acentuação que questionam práticas consideradas injustas, gostaria de destacar mais uma experiência de contestação na qual a Rede encontrou-se envolvida: o Tribunal Popular.

Um conjunto de movimentos sociais, que se diversificam de acordo com o eixo que articula sua atuação (como por exemplo, movimentos ligados a questões referentes ao acesso à terra $)^{27}$, ela-

26 Segundo um dos militantes, praticamente todos os candidatos naquele período se posicionaram contrariamente a utilização do blindado, comprometendo-se em eliminar a utilização deste equipamento caso assumissem o governo. À época da campanha eleitoral, os cinco principais candidatos ao governo estadual se posicionaram contra a utilização do "caveirão". Essa parece ter sido, ao analisar os discursos dos organizadores da campanha, a principal conquista desta, já que assim eles possuiriam a possibilidade de um questionamento face às autoridades estaduais, principalmente em relação ao governador eleito. Interessante notar que o governador eleito, apesar de ter se comprometido a retirar o "caveirão" de uso, assim que assumiu e na continuidade de seu governo, pelo contrário, intensificaria seu uso, inclusive adquirindo mais e novos caveirões.

27 Comitê contra a Criminalização da Criança e do Adolescente, Movimento 
borou um "tribunal popular" realizado no mês de dezembro de 2008, na Faculdade de Direito da Universidade de São Paulo, na cidade de São Paulo. O objetivo principal seria inverter as posições usuais nas quais habitualmente se encontram situados tanto o Estado, quanto os movimentos sociais. Ou seja, a intenção foi estabelecer um "julgamento" no qual o Estado fosse o réu principal, cuja acusação fundamental que pese contra ele fosse a violação de direitos humanos cometida por seus diversos agentes, em seus diferentes níveis de atuação, seja no executivo, no legislativo ou no judiciário.

Este tribunal toma como base de atuação diversas datas comemorativas que, coincidentemente, aglutinaram-se no ano de 2008: os 200 anos da chegada da família real ao Brasil, em 1808; os 120 anos da abolição da escravatura, em 1888; os 60 anos da Declaração Universal dos Direitos Humanos, em 1948; e, por fim, os 20 anos da atual constituição brasileira, elaborada em 1988. Para estes movimentos, o que estaria em jogo, para além da "comemoração" destas datas que marcaram passagens importantes tanto da história da humanidade, mas fundamentalmente da história do Brasil, seria a possibilidade de refletir sobre os efeitos históricos concretos destes acontecimentos, principalmente as consequiências práticas para o conjunto da população, em especial para aqueles grupos que, historicamente, foram inseridos de maneira hierárquica (e fragmentada) na estrutura social brasileira, como os negros, os índios e os moradores de favelas.

Antes de continuarmos com a explicitação das questões postas pela constituição deste tribunal, seria interessante retomar algumas reflexões anteriores. $O$ estabelecimento de um julgamento no qual o Estado é o réu e que, contra ele, pese uma série de denúncias por crimes cometidos por seus aparatos e agentes, o que parece estar em jogo é o acionamento de vocabulários convencionais e de repertórios de

Negro Unificado, Jornal Brasil de Fato, Observatório das Violências PoliciaisSP, Mandato Ivan Valente, Centro de Direitos Humanos de Sapopemba, Rede de Comunidades e Movimentos contra a Violência, Coletivo Contra Tortura, Diretório Central Estudantil/USP, Familiares de desaparecidos de maio-2006 (São Paulo), AMPARAR, APROPUC, MSLT, Por uma sociedade sem manicômios, Kilombagem, CRP-SP, Consulta Popular, Movimento dos Trabalhadores Rurais Sem-Terra, entre outros. 
justificação que, orientados a uma dada generalidade que transcende a situação do próprio julgamento, seria capaz de, no curso das disputas, definir a natureza do acordo ou desacordo que orientará e coordenará as ações dos indivíduos envolvidos com referência à justiça.

O que me parece estar em questão aqui, considerando que o desacordo também é resultado de um acordo, seria o fato de o senso de justiça destes grupos ter sido ofendido, o que justificaria o estabelecimento de um tribunal como este, no sentido de que, desta maneira, pudesse se realizar uma crítica ao modo de atuação do Estado, nos mesmos moldes pelos quais este submete a julgamento indivíduos pertencentes a categorias sociais discriminadas.

Para os movimentos que constituíram este tribunal, dois elementos articulados encontraram-se presentes e justificaram a necessidade de "julgar" o Estado: em primeiro lugar, estes grupos apontam o fato de que, a maioria dos casos de violação dos direitos humanos nos quais o Estado, de uma forma ou de outra, encontrou-se envolvido, ou estes não foram questionados, ou se o foram, não significou nenhum tipo de punição aos agentes que cometeram tais violações. Pelo contrário, o que ocorreria quase sempre, na visão destes movimentos, seria o fato de que este mesmo Estado encontra-se de forma contínua imerso em práticas, articuladas por certa compreensão da realidade, que o leva a julgar, condenar e punir consideráveis contingentes da população, muitas vezes através de formas que se encontram no limite entre o legal e o ilegal, o que permite configurações diferenciadas de acordo com a situação em questão.

Em segundo lugar, e devido ao que foi afirmado no primeiro ponto, esta forma de atuação diferenciada do Estado em certos espaços e em relação a categorias sociais como os moradores de favelas, por exemplo, tem levado, quase sempre, a uma configuração na qual estes grupos ora encontram-se impossibilitados de dar curso às suas denúncias (devido ao restrito acesso aos aparatos de justiça), ora encontram-se submetidos à intimidações que põem em risco suas próprias vidas.

Com efeito, no documento que apresenta as intenções dos vários movimentos sociais envolvidos na formação deste tribunal, é possível perceber como o julgamento que realizaram do Estado se encontrou ancorado nas mesmas práticas institucionais, visto 
que os procedimentos e os regulamentos utilizados neste processo são aqueles que este mesmo Estado utiliza quando julga qualquer um de seus cidadãos.

O planejamento de toda esta situação seguiu os trâmites usuais burocráticos: inicialmente, sessões de instrução, nas quais haveria a acusação, seguida da apresentação de provas, testemunhos e defesa. Posteriormente, a sessão final, que compreende o veredicto que condenaria ou absolveria o réu. Todavia, o que me parece mais elucidativo em todo este mecanismo elaborado por estes grupos é o que se encontra presente neste documento e que define a finalidade do tribunal:

A idéia é julgar o Estado Brasileiro por meio das leis internacionais e nacionais que ele mesmo reconhece formalmente, face às violações sistemáticas de direitos em quatro grandes áreas: violência contra movimentos e pobres do campo; violência contra a juventude pobre; violência no sistema prisional; e violência estatal sob pretexto de segurança pública nas comunidades urbanas pobres ${ }^{28}$.

Gostaria de destacar neste trecho a menção às leis internacionais e nacionais, visto que o julgamento se pautou por estas e não outras formuladas pelos movimentos em questão (embora se encontre sempre como possibilidade, para tais grupos, a constituição de um novo ordenamento moral e institucional). Como afirma Boltanski (2000), quando algum indivíduo ou grupo está em desacordo em uma situação de disputa, na qual se encontra em jogo sua posição de justiça, e descarta a violência como meio de resolução, sua discordância deve ser expressa e se apoiar em argumentos. Contudo, estes não podem valer apenas para aqueles que os enunciam, ou mesmo para alguns. Seria nesse sentido que visualizo a recorrência às leis internacionais e nacionais como o modo a partir do qual os atores em questão podem fazer referência, ajustarem-se, coordenar suas ações e assim dar curso as suas críticas.

Ainda vale ressaltar dois outros elementos importantes que configuram a realização deste tribunal e que definem sua especificidade em relação ao que usualmente se constata em situações

28 Obtido em www.tribunalpopular.org. 
de julgamento. Em primeiro lugar, seria imprescindível verificar que este tribunal pretende julgar quatro casos, que segundo os próprios organizadores do evento, são considerados "casos exemplares", no mesmo sentido apontado anteriormente, isto é, casos que encerrem em si uma série de características passíveis de serem generalizadas para outros casos semelhantes, estabelecendo certa proximidade de sentido entre eles.

Mas o que efetivamente gostaria de apontar aqui é, por um lado, o fato destes casos não se referirem apenas a um problema, mas sim a um conjunto de problemas que são classificados pelos movimentos que constituíram o tribunal como sendo aqueles que desvelam a atuação diferenciada do Estado em relação a determinados grupos e segmentos da sociedade. São eles: a chamada "Chacina do Alemão", ocorrida em 2007, originada de uma incursão policial em favelas do subúrbio do Rio de Janeiro; a situação do sistema carcerário baiano; o confronto entre policiais e um grupo de traficantes de uma quadrilha de tráfico de drogas de São Paulo, que resultou na morte de mais ou menos 500 pessoas no período de uma semana, em maio de 2006; e, por fim, a tentativa, por parte do Ministério Público do Rio Grande do Sul, amparado pela legislação sobre segurança nacional, em desarticular a atuação do Movimento dos Trabalhadores Rurais Sem-Terra, tentando classificá-lo como terrorista.

Por outro lado, a apresentação destes casos expressa o esforço de alguns movimentos sociais de origens diversas em se articularem, ampliando a rede de denúncias para além de suas lutas específicas e cidades e localidades de atuação, o que sugere a intenção de gerar uma aproximação entre as variadas demandas existentes e assim possibilitar outro encaminhamento delas, ao menos no sentido de criar um espaço no qual estes movimentos possam apresentar sua compreensão daqueles fatos e apontar para outro ordenamento societário no qual haja o respeito a garantias mínimas, como o direito à vida. Além do mais, o que os aproximaria e autorizaria o julgamento em conjunto seria o fato de terem sido todos originados da atuação de um arranjo institucional específico: o Estado brasileiro.

Aproveito esta afirmação para apresentar o segundo elemento que diferencia este julgamento dos demais. $\mathrm{O}$ réu em questão (o Estado brasileiro), apesar de, assim como todos os outros réus, ter 
o direito a defesa garantido e todo o processo, como afirmado anteriormente, guiar-se por regras nacionais e internacionais que regulam o estabelecimento do júri, tem um posicionamento especial em toda esta situação: o veredicto em relação a ele já se encontra definido antes mesmo do início do julgamento, isto é, o Estado é considerado culpado e todo o desenrolar da situação é para demonstrar isto ${ }^{29}$.

Por fim, gostaria de tecer ainda alguns comentários acerca dos pressupostos deste tribunal. Em primeiro lugar, como afirma Doimo (1995) e já apontado anteriormente, os movimentos costumam oscilar, em suas práticas, entre o que a autora classificou de face "expressivo-disruptiva", isto é, aquela que mobiliza um conjunto de valores e ações que tendem a deslegitimar a atuação do Estado, e a face "integrativo-corporativa", através da qual buscam integrar-se a estrutura estatal pela via do acesso a bens e serviços de cidadania. Esta dinâmica ambivalente da ação destes movimentos parece estar presente quando consideramos a realização deste tribunal. Estes grupos que se mobilizaram e organizaram tal espaço de interlocução e protesto, apesar de apontarem para outros valores que não aqueles que articulam e justificam os crimes julgados neste tribunal, parecem se referir, em última instância, ao próprio Estado. Ao mesmo tempo em que realizam uma crítica aos fundamentos que norteiam a atuação deste, exigem-lhe que garanta e efetive os bens e serviços de cidadania que se encontram negados ou são oferecidos parcialmente a certos segmentos da sociedade.

\section{Considerações finais}

O objetivo deste artigo foi apresentar como determinados atores sociais formaram a luta contra a violência policial no Rio de

29 Embora se possa considerar o fato de que muitos dos julgamentos cotidianos que ocorrem em nossas cortes também ofereçam, de alguma maneira, a sentença de antemão, especialmente quando se leva em consideração a presença de certas categorias sociais (como os moradores de favelas, por exemplo), não se deve esquecer que toda burocracia possui seus trâmites e rituais obrigatórios e que são seguidos, de determinada forma, ainda que aquele que proferirá a sentença esteja motivado previamente (muito provavelmente orientado pela visão dominante acerca do grupo social a qual pertence o julgado) em condenar. 
Janeiro, explicitando o formato de atuação na qual ela se expressa: o formato em rede. Deste modo, realizar uma análise da constituição da ação coletiva a partir deste formato contribuiu para a compreensão do processo de publicização posto em marcha pela experiência de ação coletiva analisada neste trabalho.

Ao considerar a constituição desta experiência a partir do formato em rede, pretendi apontar as dificuldades e possibilidades de ascensão de um certo problema privado no sentido dele se tornar público. Destarte, envolvia considerar o que Freire (2005), a partir das contribuições de Gusfield, aponta como sendo um problema social ou um problema público.

Um problema social (como no caso da segurança e num nível mais geral o acesso à cidade e aos direitos de cidadania) não é necessariamente um problema que se poderia chamar de público. Ao se falar em problema social, ressalta-se uma determinada condição reconhecida como sendo problemática por certos grupos de uma dada sociedade. Todavia, essa condição não é uma condição necessária para transformar-se em um problema público, visto que "não se torna necessariamente um assunto que precisará sempre de uma resposta pública” (Freire, 2005, p.40). Para tanto, observei os processos pelos quais essa temática foi construída pelos atores envolvidos, assim como as consequiências tanto para a forma de organização interna (das favelas) quanto para o restante da cidade no sentido do reconhecimento público destas demandas.

Boltanski (2000) afirma que, no processo de transformação de um problema particular em um problema público, o denunciante deveria convencer outras pessoas, trazê-las e as unificar ao seu protesto, mobilizá-las e, para isso, assegurar-lhes que diz não somente a verdade, mas também deixar claro que esta deve e merece ser dita e que a acusação está à altura da injustiça denunciada. Todavia, a denúncia pode fracassar ou se frustrar se aquele que denuncia não encontra outros indivíduos dispostos a segui-lo.

As experiências de mobilização política observadas tanto na Campanha contra o Caveirão, quanto no Tribunal Popular expressam o fato de que o autor de uma denúncia pretende ser seguido por uma quantidade não definível, embora elevado, de 
outros indivíduos. A causa que ele defende e que ele almeja ser reconhecida coletivamente encerra uma pretensão de universalidade. A partir de um caso singular (que, no entanto, pode ser transformado num caso exemplar) reporta-se a todos, de maneira que não haveria limites naturais à estatura (ou importância coletiva) que podem tomar os casos.

O processo de publicização de um caso, isto é, a capacidade dele ascender ao geral e, desta maneira, exigir respostas públicas pode ser observado a partir das inúmeras interconexões e da trama construída pela atuação da Rede de Comunidade e Movimentos contra a Violência. Pude perceber que a essa construção estava subjacente o desejo dos atores envolvidos neste processo em garantir visibilidade aos casos de violação dos direitos humanos em favelas do Rio de Janeiro. A constituição desta experiência de ação coletiva a partir do formato em rede parece favorecer, em parte, a luta contra a violência policial, haja vista a capacidade que os atores e grupos envolvidos apresentam no sentido do estabelecimento de alianças as mais diversas no conjunto da sociedade e também no interior de instituições públicas.

Recebido em: 15.1.2010

Aprovado em: 23.7. 2010

\section{Referências}

AGUIAR, S. Redes sociais e tecnologias digitais de informação e comunicação. Relatório de Pesquisa. Núcleo de Pesquisas, Estudos e Formação da Rede de Informações para o Terceiro Setor, 2006. BOLTANSKI, L \& THÉVENOT, L. De la justification. Les économies de la grandeur. Paris: Gallimard, 1991.

BOLTANSKI, L. El amor y la justicia como competencias: tres ensayos de sociologia de la acción. Buenos Aires: Amorrortu Editores, 2000.

. De la critique. Précis de sociologie de l'émancipation. Paris: Gallimard, 2009. 
BREVIGLIERI, M. \& STAVO-DEBAUGE, J. Le Geste Pragmatique de la Sociologie Française. Autour des Travaux de Luc Boltanski et Laurent Thévenot. Antropolítica, no 7, pp. 7-22, 1999.

CALDEIRA, T.P.R. Cidade de muros: Crime, segregação e cidadania em São Paulo. 2.ed. São Paulo: Ed. 34/Edusp, 2000.

CEFAÍ, D. Pourquoi se mobilise-t-on? Les théories de l'action collective. Paris : La Découverte, 2008.

CUNHA SILVA, M.M. Meninas à prova: um estudo sobre as justificações de adolescentes em conflito com a lei. Dissertação de Mestrado. Universidade Federal Fluminense. 2008.

DAGNINO, E. Cultura, cidadania e democracia. In: Alvarez, S.E.; DAGNINO, E. \& ESCOBAR, A. (Orgs.). O Cultural e o Político nos Movimentos Sociais Latino-Americanos. Cultura e Política nos Movimentos Sociais Latino-Americanos. Belo Horizonte: Editora UFMG, 2000.

DOIMO, A.M. A vez e a voz do popular. Movimentos sociais e participação política no Brasil pós-70. Rio de Janeiro: Relume Dumará/ANPOCS, 1995.

GARCIA, T.C. Denúncias públicas contra a violência policial no Rio de Janeiro. Dissertação de Mestrado. Instituto Universitário de Pesquisas do Rio de Janeiro, 2009.

FARIAS, J. Movimento 'Posso me identificar?': de objetos da violência a sujeitos da política. Monografia de bacharelado - Departamento de Ciências Sociais, IFCH. Rio de Janeiro: UERJ, 2004.

. Estratégias de visibilidade, política e movimentos sociais: reflexões de sobre a luta de moradores das favelas cariocas contra a violência policial. Dissertação de Mestrado. Programa de Pósgraduação em Ciências Sociais Rio de Janeiro: UERJ, 2006.

FREIRE, J. Sensos do justo e problemas públicos em Nova Iguaçu. Tese de Doutorado, IUPERJ, mimeo, 2005.

LAVALLE, A.G.; CASTELlO, G. \& BICHIR, R.M. Protagonistas na Sociedade Civil: Redes e Centralidades de Organizações Civis em São Paulo. Dados, vol. 50, no 3, pp. 465-498, 2007.

LEITE, M.P. Entre o individualismo e a solidariedade: dilemas da política e da cidadania no Rio de Janeiro. Revista Brasileira de Ciências Sociais, vol. 15, noํ4, 2000. 
MAGALHÃES, A.A. Entre a vida e a morte: a luta! A construção da ação coletiva por moradores de favelas do Rio de Janeiro. Dissertação de Mestrado, IUPERJ, mimeo, 2008.

MACHADO DA SILVA, L.A. \& LEITE, M. Favelas e democracia: temas e problemas da ação coletiva nas favelas cariocas. In: MACHADO DA SILVA, L.A et al. (orgs.). Rio: a democracia vista de baixo. Rio de Janeiro: IBASE, 2004.

. Violência, crime e polícia: o que dizem os favelados quando falam desses temas? In: Machado da Silva, Luís Antônio (org.) Vida sob Cerco: violência e rotina nas favelas do Rio de Janeiro. Rio de Janeiro: Nova Fronteira, 2008.

MARQUES, E.C. Redes sociais e poder no Estado brasileiro: aprendizados a partir das políticas urbanas. Revista Brasileira de Ciências sociais, vol. 21, no 0 6, pp. 15-41, 2005.

SOARES, L.E. et al. Violência e política no Rio de Janeiro. Rio de Janeiro: Relume-Dumará/ISER, 1996.

SHERER-WARREN, I. Redes de Movimentos Sociais. São Paulo: Edições Loyola, 1993.

VALLADARES, L.P. A invenção da favela. Do mito de origem a favela. com. 1.ed. Rio de Janeiro: FGV, 2005.

VANDENBERGUE, F. Construção e crítica na nova sociologia francesa. Revista Sociedade e Estado. Vol. 21, no 2, pp. 315-366, maio/agosto, 2006.

WERNECK, A.V. O invento de Adão: O papel do ato de dar uma desculpa na manutenção das relações sociais. Tese de Doutorado. Universidade Federal do Rio de Janeiro. 2009.

\footnotetext{
Abstract

Transversality in collective action: network experience as a possibility for critique and public voice

This article presents some of the conclusions emerging from my master's thesis, in which I seek to understand how Rio de Janeiro shantytown inhabitants have built their struggle against police violence. For these purposes, I use data collected while accompanying the actions of the social movement referred to as Community and Movement Network Against Violence (Rede
} 
de Comunidades e Movimentos contra a Violência). My analysis attempts to reveal the processes through which certain demands are brought to the public eye and subaltern social segments gain access to the public space. The axis that will enable us to describe and interpret the countless actions and articulations carried out by different groups in their fight against police violence in the shantytowns of this city and which enables us to interpret such processes of gaining public access and attention can be found in the format that such activities have taken on, that is, the network.

Keywords: slums, collective action, networks, public voice. 
